\title{
Microwave-Assisted Alkaline Pretreatment and Microwave Assisted Enzymatic Saccharification of Oil Palm Empty Fruit Bunch Fiber for Enhanced Fermentable Sugar Yield
}

\author{
Saifuddin M. Nomanbhay ${ }^{*}$, Refal Hussain, Kumaran Palanisamy \\ Centre for Renewable Energy, Universiti Tenaga Nasional, Selangor, Malaysia \\ Email: ${ }^{*}$ saifuddin@uniten.edu.my
}

Received January 23, 2013; revised February 26, 2013; accepted March 8, 2013

\begin{abstract}
Lignocellulosic materials are promising alternative feedstocks for bioethanol production. However, the recalcitrant nature of lignocellulosic biomass necessitates an efficient pretreatment pretreatment step to improve the yield of fermentable sugars and maximizing the enzymatic hydrolysis efficiency. Microwave pretreatment may be a good alternative as it can reduce the pretreatment time and improve the enzymatic activity during hydrolysis. The overall goal of this paper is to expand the current state of knowledge on microwave-based pretreatment of lignocellulosic biomass and microwave assisted enzymatic reaction or Microwave Irradiation-Enzyme Coupling Catalysis (MIECC). In the present study, a comparison of microwave assisted alkali pretreatment was tried using Oil Palm empty fruit bunch. The microwave assisted alkali pretreatment of EFB using $\mathrm{NaOH}$, significantly improved the enzymatic saccharification of EFB by removing more lignin and hemicellulose and increasing its accessibility to hydrolytic enzymes. The results showed that the optimum pretreatment condition was $3 \%(\mathrm{w} / \mathrm{v}) \mathrm{NaOH}$ at $180 \mathrm{~W}$ for 12 minutes with the optimum component loss of lignin and holocellulose of about $74 \%$ and $24.5 \%$ respectively. The subsequent enzymatic saccharification of EFB pretreated by microwave assisted $\mathrm{NaOH}(3 \% \mathrm{w} / \mathrm{v})$; resulted in $411 \mathrm{mg}$ of reducing sugar per gram EFB at cellulose enzyme dosage of $20 \mathrm{FPU}$. The overall enhancement by the microwave treatment during the microwave assisted alkali pretreatment and microwave assisted enzymatic hydrolysis was 5.8 fold. The present study has highlighted the importance of well controlled microwave assisted enzymatic reaction to enhance the overall reaction rate of the process.
\end{abstract}

Keywords: Lignocellulosic; Empty Fruit Bunch-EFB; Saccharification; Microwave Assisted Reaction; Non Thermal Effects

\section{Introduction}

Our society relies on fossil fuels for its energy needs. Any event that threatens their availability influences the cost of petroleum supply. Additionally, the negative impact of fossil fuels on the environment, particularly greenhouse gas emissions, has imposed a critical need on the society to identify and develop renewable fuel alternatives [1]. Fuel ethanol produced from renewable biomass, such as sugar, starch, or lignocellulosic materials, is one of the alternative energy resources that are both renewable and environmentally friendly [2]. The US government has identified ethanol produced from lignocellulosic materials as the most promising renewable energy source [3]. Lignocellulosic materials are the most abundant biopolymer in nature and those that show potential for ethanol production include agricultural residues (i.e.

"Corresponding author. corn stover, wheat straw, rice straw), agricultural byproducts (i.e. corn fiber, rice hull, sugarcane bagasse), and dedicated energy crops (i.e. switchgrass, sweet sorghum, high fiber sugarcane) [4]. Ethanol can be blended with fossil petrol (E5, E10, E85) or used as neat alcohol in dedicated engines, taking advantage of the higher octane number and higher heat of vaporisation [5]. Internal combustion engines operating on ethanol also produce fewer greenhouse gas (GHG) emissions since ethanol is less carbon-rich than gasoline. In view of the current global fuel reserve, the United States alone targeted to blend 7.5 billion gallons of renewable fuels into gasoline by 2012 , and by far, the most common renewable fuel is ethanol following the US energy policy act, 2005 [6].

Processing of palm for oil extraction leads to the formation of several by-products and residues. The palm trunks and fronds, empty fruit bunches (EFB), pressed 
fruit fibers (mesocarp fibers), shells and palm oil mill effluent (POME), which is produced at the palm oil mill, have economic values. In the past, these products of oil palm were not effectively utilised and in many instances had caused severe pollution problems. The empty fruit bunches (EFB) are the solid residue that is produced in the highest amount from the fresh fruit bunches (FFB) of oil palm. Oil palm is the largest plantation sector in Malaysia. It accounts for about 17.08 million tones of lignocellulosic materials in the form of empty fruit bunch (EFB) which are produced from the oil palm processing industries [7]. Using the lignocellulosic solid wastes of the palm oil mill industry, many researchers have already come up with some laboratory scale output of different products such as composting [8], activated carbon [9], citric acid [10] and gasification [11]. Empty fruit bunch (EFB) is a complex lignocelllulosic material consists of $41.3 \%-46.5 \%$ cellulose, $25.3 \%-33.8 \%$ hemicelluloses and $27.6 \%-32.5 \%$ lignin [12]. Cellulose, is a linear biopolymer of anhydroglucopyranose-molecules, connected by $\beta$-1,4-glycosidic bonds. Hemicelluloses, the second most abundant component of lignocellulosic biomass, are heterogeneous polymers of pentoses, hexoses and sugar acids. Lignin, the third main heterogeneous polymer in lignocellulosic residues, acts as a barrier for any solutions or enzymes by linking to both hemicelluloses and cellulose. This lignocellulosic material has a great potency as raw materials for the fermentative production of bioethanol. Processing of lignocellulosics to bioethanol consists of four major unit operations: 1) pretreatment, 2) hydrolysis, 3) fermentation, and 4) product separation/ distillation.

The main challenge of saccharification of the EFB is the hemicellulose and lignin content [10]. Pretreatment of lignocellulose is a key step for the efficient utilization of biomass for ethanol production. This step is very important to make the lignocellulosic material amenable to subsequent hydrolysis process [1]. Current world bioethanol research is driven by the need to reduce the costs of production. Reducing ethanol production cost, requires optimizing pre-treatment strategies to the most economical possible [13]. An effective pretreatment of these lignocellulosic materials is needed to liberate the cellulose from the lignin seal and at the same time to reduce the lignin content, to reduce cellulose crystallinity and to increase cellulose porosity $[14,15]$. Pretreatment process releases complex cellulosic materials which will then undergo enzymatic saccharification process to yield simple sugar followed by fermentation of the sugars to ethanol. A number of pretreatment methods have been developed for improving hydrolysis of lignocellulosic biomaterials. Most of these technologies suffer from relatively low sugar yields, severe reaction conditions, large capital investment, high processing costs and great investment risks [16,17]. Acid pretreatment is able to hydrolyze the cellulose and hemicelluloses but capital cost is high because of the formation of inhibitors and equipment corrosion problems [18]. Oxidative pretreatment usually results in losses of cellulose and hemicellulose due to the fact that all oxidants used are non selective [19]. Pretreatment with organic solvents is too expensive to be employed for biomass though pure lignin could be obtained as a byproduct through this processing technology [20]. Biological pretreatment which commonly involves the use of the white-rot fungus to degrade lignocelluloses requires low energy input, low capital cost and mild environmental conditions. However, it is otherwise unattractive at industrial scale because of slow conversion rates [1,21]. Extensive reviews on pretreatment process methods and the use of these technologies for pretreatment of various lignocellulosic biomass are given by $[4,16,17,21,22]$.

Microwave irradiation has been widely used in many areas because of its high heating efficiency and easy operation. Advantages of microwave-based technologies include reduction of process energy requirements, uniform and selective processing, and the ability to start and stop the process instantaneously [23,24]. The earliest known study involving microwave pretreatment examined the effect of microwave radiation on rice straw and bagasse immersed in water and reported an improvement in total reducing sugar production by a factor of 1.6 for rice straw and 3.2 for bagasse in comparison to untreated biomass [25]. Some studies have shown that microwave irradiation could change the ultrastructure of cellulose [26], degrade lignin and hemicelluloses in lignocellulosic materials, and increase the enzymatic susceptibility of lignocellulosic materials [24,26,27]. [14] reported that when using microwave-assisted alkali pretreatment of wheat straw, lower sugars losses and higher hydrolysis rates than conventional alkali pretreatment methods were observed [14]. Most microwave pretreatment is generally carried out at elevated temperature $\left(>160^{\circ} \mathrm{C}\right)$. Some previous studies have shown that application of microwave irradiation pretreatment may significantly increase the conversion of starch materials to glucose $[14,28]$. Combination microwave treatment with either acid or alkali or combined acid/alkali might be an alternative for pretreatment of lignocellulosic materials has been recently explored [14,24,29].

Microwave assisted enzymatic reactions or also called as Microwave Irradiation-Enzyme Coupling Catalysis (MIECC) reactions have been proven as a useful tool for many enzymatic transformations in both aqueous and organic solutions [30-32]. It has been proposed that in case of low power of high-frequency electromagnetic field the nonthermal activation of enzyme may be observed $[33,34]$. The study of enzymes working at micro- 
wave conditions is of great importance from both the scientific and industrial view point.

The objective of this study is to evaluate the efficiency of pretreatment and enzymatic hydrolysis by combination of microwave-alkali and Microwave IrradiationEnzyme Coupling Catalysis (MIECC) on EFB to enhance fermentable sugar production.

\section{Materials and Methodology}

\subsection{Materials and Reagents}

Oil palm EFB were collected from Seri Ulu Langat Palm Oil Mill in Dengkil, Selangor, Malaysia. EFB obtained after fruit extraction were sent to the laboratory without drying and/or milling.

The chemical reagents were of analytical grade and used without further purification. Sodium hydroxide was purchased from Merck; acetic acid, sulfuric acid, calcium chloride, ammonium sulphate, magnesium sulphate, anhydrous ethanol, calcium hydroxide and anhydrous glucose were purchased from J. T. Baker.

Microwave treatments were carried out using a domestic microwave oven (Samsung, CE2877 N, Korea) with an operating frequency of $2450 \mathrm{MHz}$. The microwave oven provided microwave radiation at variable power levels of $100 \mathrm{~W}, 180 \mathrm{~W}, 300 \mathrm{~W}, 450 \mathrm{~W}, 600 \mathrm{~W}$ and 850 $\mathrm{W}$.

\subsection{Methods}

\subsubsection{Raw Material Conditioning}

Collected EFB samples were washed with distilled water vigorously to remove all mud, dust and other unwanted substances. Washed sample was dried in oven at $105^{\circ} \mathrm{C}$ for $24 \mathrm{~h}$ to get constant dry weight. Dried EFB fiber was ground with milling machine to obtain desired particle size of 1 - $2 \mathrm{~mm}$ (No. 18 mesh sieve). The milled EFB samples were stored in sealed plastic bag at room temperature until used for pretreatment.

\subsubsection{Raw Material Characterization}

The total lignin content was determined as the sum of acid insoluble lignin (or Klason lignin) and acid soluble lignin contents and were determined by the NREL procedure [35]. Acid insoluble lignin was determined gravimetrically as the ash-free acid insoluble residue resulting from the hydrolysis. Briefly the method employs two-step acid hydrolysis to fractionate the biomass into acid soluble and acid insoluble fractions. The samples hydrolysis consisted of sequential acid hydrolysis procedure utilizing $72 \% \mathrm{H}_{2} \mathrm{SO}_{4}$ at $30^{\circ} \mathrm{C}$ for $1 \mathrm{~h}$ and followed by $4 \% \mathrm{H}_{2} \mathrm{SO}_{4}$ at $121^{\circ} \mathrm{C}$ for $1 \mathrm{~h}$, leaving the majority of the lignin as an insoluble residue that is quantified gravimetrically. The acid soluble portion of the lignin is then quantified using ultraviolet-visible spectrophotometry. Acid soluble lignin was calculated using the hydrolysis liquor aliquot obtained. Absorbance was measured at $320 \mathrm{~nm}$ on a UV-Visible spectrophotometer using a $1 \mathrm{~cm}$ path length quartz cuvette. The sample was diluted as necessary to bring the absorbance into the range of 0.7 - 1.0. Deionized water was used to dilute the sample, and also served as the blank solution. Lignin concentration was calculated based on the following equation [35].

$$
\begin{aligned}
& \% \text { Acid Soluble lignin } \\
& =\frac{\text { Abs } \times \text { Volume } \times \text { Dilution }}{\varepsilon \times \mathrm{W}} \times 100
\end{aligned}
$$

where;

Abs = average UV-vis absorbance for the sample (in triplicate) at $320 \mathrm{~nm}$;

Volume $=$ volume of filtrate (sample);

$\varepsilon=$ Absorptivity of lignin at specific $320 \mathrm{~nm}$ wavelength-(30 L/g.cm);

$\mathrm{W}=$ weight of sample in milligrams.

The insoluble portion of the sample from the previous acid treatment was used to determine the acid insoluble lignin fraction using gravimetric method. The insoluble fraction from the acid hydrolysis was dried in an oven at $105^{\circ} \mathrm{C}$ for $12 \mathrm{~h}$. The crucible was cooled in a desiccator for $15 \mathrm{~min}$ and then weighed accurately. Lignin (acid insoluble) was calculated as follows:

$$
\begin{aligned}
& \% \text { Acid insoluble lignin } \\
& =\frac{\text { Final weight after treatment }}{\text { Initial weight of sample }} \times 100
\end{aligned}
$$

Holocellulose was determined with the chlorination method described by the [36]. In a typical procedure, $1 \mathrm{~g}$ of sample was placed in an Erlenmeyer flask $(300 \mathrm{~mL})$ and $150 \mathrm{~mL}$ of distilled water was added. While slowly shaking, $1 \mathrm{~g}$ of $\mathrm{NaClO}_{2}$ and $0.2 \mathrm{~mL}$ of acetic acid were added and the flask was covered with glass and boiled at $70^{\circ} \mathrm{C}$ to $80^{\circ} \mathrm{C}$ for $60 \mathrm{~min}$. Again, $1 \mathrm{~g}$ of $\mathrm{NaClO}_{2}$ and 0.2 $\mathrm{mL}$ of acetic acid were added and boiled 3 times. After cooling, the sample was filtered using a filter flask and washed with hot water until free of acid. Afterward, the insoluble portion was dried in an oven at $105^{\circ} \mathrm{C}$ for $4 \mathrm{~h}$, cooled in a desiccator and weighed, repeatedly until obtaining a constant weight. Holocellulose content was calculated as follows:

$$
\begin{aligned}
& \text { Holocellulose content }(\%) \\
& \frac{\text { Final weight after treatment }}{\text { Initial weight of sample }} \times 100
\end{aligned}
$$

Cellulose was calculated after holocellulose content determination by further treating the obtained fibers with sodium hydroxide and acetic acid. Hemicellulose content 
was calculated by subtracting the cellulose content from the holocellulose content.

\subsubsection{Pretreatment}

Alkaline pretreatment of EFB fiber was carried out in $250 \mathrm{~mL}$ glass bottles with screw cap. 3\% (w/v) $\mathrm{NaOH}$ (100 mL) was added to milled EFB samples (1:10 solid to liquid ratio). With the cap of the bottles slightly loose, the samples were heated by subjecting to microwave treatment in a microwave oven. Output power was set at $180 \mathrm{~W}$ and the exposure time was varied at 3, 6, 9, 12, 15, 18 and $21 \mathrm{~min}$. This power level was chosen since it allowed for sufficient lengths of pretreatment time without drastic volumetric losses of the liquid phase. After pretreatment reaction, the samples were filtered to separate the insoluble solid fiber from the soluble fraction. The insoluble solid fiber was washed with water until neutral $\mathrm{pH}$, and dried at $105^{\circ} \mathrm{C}$ for $4 \mathrm{hr}$. The fiber was then determined for its lignin, cellulose and hemicelluloses sugar contents. The decrease in lignin, cellulose, and hemicellulose after microwave-alkaline pretreatment were calculated. For comparison similar treatment with $3 \%$ $\mathrm{NaOH}$ was performed by heating in the water bath at $50^{\circ} \mathrm{C}$ for $20,40,60,80,100$ and $120 \mathrm{~min}$ (without the microwave).

\subsubsection{FTIR Analysis}

Fourier Transform Infrared spectroscopic (FTIR) analysis was performed to detect changes in functional groups that may have been caused by the pretreatment process. FTIR analysis was carried using a Schimadzu Spectrometer with detector at $4 \mathrm{~cm}^{-1}$ resolution and 25 scan per sample. Discs were prepared by mixing $3 \mathrm{mg}$ of dried sample with $300 \mathrm{mg}$ of $\mathrm{KBr}$ (Spectroscopic grade) in an agate mortar. The resulting mixture was successfully pressed at $10 \mathrm{Mpa}$ for $3 \mathrm{~min}$ to produce a pellet which was then used for the analysis.

\subsubsection{Enzymatic Hydrolysis (Saccharification)}

The EFB biomass pretreated by $3 \%(\mathrm{w} / \mathrm{v}) \mathrm{NaOH}$ solution and microwave at the optimal time (the duration of microwave exposure that gave highest lost of lignin content of the EFB during the alkali pretreatment) was chosen for further experiments. These were subjected to enzymatic saccharification which was carried out using commercial cellulase (6.0 FPU, (Filter Paper Unit)/mg) from Trichoderma reesei (E.C. 3.2.1.4). The cellulose enzyme was supplemented with $\beta$-glucosidase or cellobiase (250 U/ $\mathrm{mL}$ ) from Aspergillus niger (E.C. 3.2.1.21). The enzymes were obtained from Novozyme North America, Inc. (Franklinton, NC, USA). The addition $\beta$-glucosidase (cellobiase) was necessary to mitigate cellobiose inhibition of cellulase [37]. Cellobiose is a disaccharide consisting of two glucose molecules linked by a $\beta(1 \rightarrow 4)$ glyco- side bond.

The enzymatic saccharification of the pretreated EFB was performed by soaking $5 \mathrm{~g}$ of pretreated EFB in 100 $\mathrm{mL}$ of $0.05 \mathrm{M}$ citrate phosphate buffer ( $\mathrm{pH} 5.0)$. The sample was shaken in a mechanical shaker for $40 \mathrm{~min}$ at $150 \mathrm{rpm}$. A dose of $0.005 \%$ sodium azide was introduced to avoid any microbial contamination; and $1.0 \%(\mathrm{v} / \mathrm{v})$ of Tween 80 was added to facilitate the enzymatic action. Seven separate samples were loaded with cellulase $(5,10$, $15,20,25,30,35$, FPU) per gram of pretreated EFB biomass. The $\beta$-glucosidase was loaded with a constant concentration of $40 \mathrm{U}$ per gram of pretreated solid EFB for all the seven samples. The mixture was shaken in a mechanical shaker for $3 \mathrm{~min}$ at $150 \mathrm{rpm}$.

The mixtures were then subjected to the microwave treatment at output power of $100 \mathrm{~W}$ in a microwave oven (Samsung, CE2877 N, Korea) and the hydrolysis was carried out for $4 \mathrm{hr}$ which consisted of a 1 min break after every 10 minutes microwave exposure. During the 1 min break, the sample mixture was removed from the microwave oven and mixed well using a mechanical shaker $(150 \mathrm{rpm})$. After $1 \mathrm{~min}$ of mixing the sample was put back into the microwave oven and exposed to microwave irradiation for another $10 \mathrm{~min}$. The $10 \mathrm{~min}$ cycle was continued until the $4 \mathrm{hr}$ of incubation time was reached (about 24 cycles). After the $4 \mathrm{hr}$ hydrolysis with microwave treatment at $100 \mathrm{~W}$, the flasks were kept in a water bath at $50^{\circ} \mathrm{C}$ for up to $5 \mathrm{~min}$. At the end of $5 \mathrm{~min}$, the supernatant was used to estimate the reducing sugar released for each flask. The reducing sugar was estimated by 3,5-dinitrosalicylic acid (DNS) method [38]. The result expressed in miligram of reducing sugar per gram of pretreated biomass. A standard curve was drawn by measuring the absorbance of known concentrations of glucose solutions at $570 \mathrm{~nm}$. All experiments were conducted in duplicate.

The result will indicate the optimal amount of cellulase enzyme required for hydrolysis under microwave irradiation to achieve the highest amount of reducing sugar. The control samples were not subjected to the microwave irradiation, but were incubated at $50^{\circ} \mathrm{C}$ in a shaking water bath $(120 \mathrm{rpm})$ and incubated for $48 \mathrm{hr}$. The supernatant was analyzed for reducing sugars as before after the end of the incubation period.

\section{Results and Discussion}

\subsection{Characterization of EFB}

Characterization of EFB was carried out to determine major of principal components of EFB and the composition is shown in Table 1. As can be seen, the highest compositional content, in dry-weight basis, was holocellulosic (cellulose + hemicellulose) component ( $\sim 50 \%)$. This shows that EFB is suitable as a potential feedstock 
Table 1. Composition of oil palm empty fruit bunches (EFB) fiber.

\begin{tabular}{ccc}
\hline Number & Component & Content (wt\%) \\
\hline 1 & Lignin & $24 \%-26.6 \%$ \\
2 & Cellulose & $22.5 \%-25.3 \%$ \\
3 & Hemicellulose & $24.5 \%-27.8 \%$ \\
4 & Moisture & $8 \%-10 \%$ \\
5 & Other components & $14 \%-16 \%$ \\
\hline
\end{tabular}

for ethanol production. The lignin content was nearly half of the holocelulosic composition and comparable to lignin contents of hardwoods [12]. This level of lignin is considered high and hence the main reason of alkali pretreatment applied to oil palm EFB. The main effect of alkali pretreatment on lignocellulosic biomass is delignification by breaking ester bonds cross-link lignin and xylan, thus increasing the porosity of the biomass [39]. Reducing lignin content can increase enzyme accessibility to biomass substrate during hydrolysis [40]. A key to pretreatment is finding the proper process conditions which will remove most of the lignin while preserving the sugars.

\subsection{Pretreatment}

Particle size reduction increases the surface area to volume ratio and improves enzyme accessibility to the active binding sites for the subsequent enzymatic hydrolysis and fermentation steps. It was reported by [41] that a higher lignin removal was observed with smaller particle size biomass, however about $5 \%$ sugars were also lost because of the larger reacting surface area of biomass particles. Their observation showed that the size between $1-2 \mathrm{~mm}$ biomass sizes gave the best results in terms of maximum delignification and minimum lost of sugar. In this study we have also chosen the biomass fiber size between $1-2 \mathrm{~mm}$. The milling of lignocellulose, however, is energy intensive and increases the pretreatment cost [42].

The two most commonly studied chemical methods in the pretreatment of lignocellulosic biomass are the acid and alkaline pretreatments. Acid pretreatment results in disruptions of covalent bonds, hydrogen bonds and van der Waals forces, that, hold together the biomass components. This consequently, causes solubilization of hemicellulose and reduction of cellulose crystallinity [43]. In contrast, alkaline pretreatment causes delignification of biomass and make the lignocellulose swollen through saponification reactions [44]. Unlike acid pretreatment, alkaline pretreatment has been proven effective within a wide temperature range at various concentrations [44]. Lignin dissolves at temperatures between $140^{\circ} \mathrm{C}$ and $160^{\circ} \mathrm{C}$. It was reported that as temperature increased above $130^{\circ} \mathrm{C}$, more than $40 \%$ lignin was removed [41]. However, the loss of both cellulose and hemicelluloses also increases with increasing temperature [45]. A key to pretreatment is finding the proper process conditions which will remove most of the lignin while preserving the sugars. The softening and dissolving temperature range of lignin can be lowered by the presence of acid, alkaline or ammonia [45]. The use of dielectric heating (microwave) instead of conventional heating as means of pretreatment was first reported by [25]. Alkaline pretreatment of lignocellulosic biomass is an effective pretreatment method which predominantly affects lignin content of biomass. During delignification, the sodium hydroxide $(\mathrm{NaOH})$ breaks the ester bonds cross-linking lignin and xylan, thus increasing the porosity of biomass [39]. It was reported that during alkali pretreatment of wheat straw, with microwave assisted heating, lower sugars losses and higher hydrolysis rates were observed than compared to alkali pretreatment with conventional heating method [14].

The loss of lignin in the pretreatment is one of the most important indicators of pretreatment effectiveness because the presence of lignin impedes enzymatic hydrolysis of the carbohydrates [4]. Lignin interferes with hydrolysis by blocking the access of cellulases to cellulose and by irreversibly binding hydrolytic enzymes [3]. Figures 1 and 2, show the degradation of lignin and holocelluloses in the EFBs fiber after $\mathrm{NaOH}$ pretreatment. The results shown are represented as the component loss of lignin and holocelluloses. The results showed that the optimum pretreatment condition was $3 \%(\mathrm{w} / \mathrm{v}) \mathrm{NaOH}$ at $180 \mathrm{~W}$ for 12 minutes with the optimum component loss of lignin and holocellulose of about $74 \%$ and $24.5 \%$ respectively. Figure 1 showed that the increase of heating time only affected the loss of lignin and hemicellulose from $3 \mathrm{~min}$ to $12 \mathrm{~min}$ and there was no significant effect of heating time after 12 minutes pretreatment on the loss of lignin and holocelluloses. While for treatment without microwave (Figure 2), it can be seen that the optimum pretreatment condition was at $50^{\circ} \mathrm{C}$ using $3 \% \mathrm{NaOH}$ for $80 \mathrm{~min}$, with the optimum component loss of lignin and hemicellulose of about $69 \%$ and $23.5 \%$ respectively. The result is similar to the one obtained for the microwave assisted alkali treatment (180 Watt, $12 \mathrm{~min}$ ). In is interesting to note that, these results compared to conventional $\mathrm{NaOH}$ pretreatments, were obtained at only oneseventh of the residence time. The power level of $180 \mathrm{~W}$, was chosen since it allowed for sufficient lengths of pretreatment time without drastic volumetric losses of the liquid phase and charring of the solid sample did not occur even at $25 \mathrm{~min}$ of treatment time. It has been reported that during microwave assisted alkaline treatment at 850 W with $15 \%$ solid loading, charring of the samples oc- 


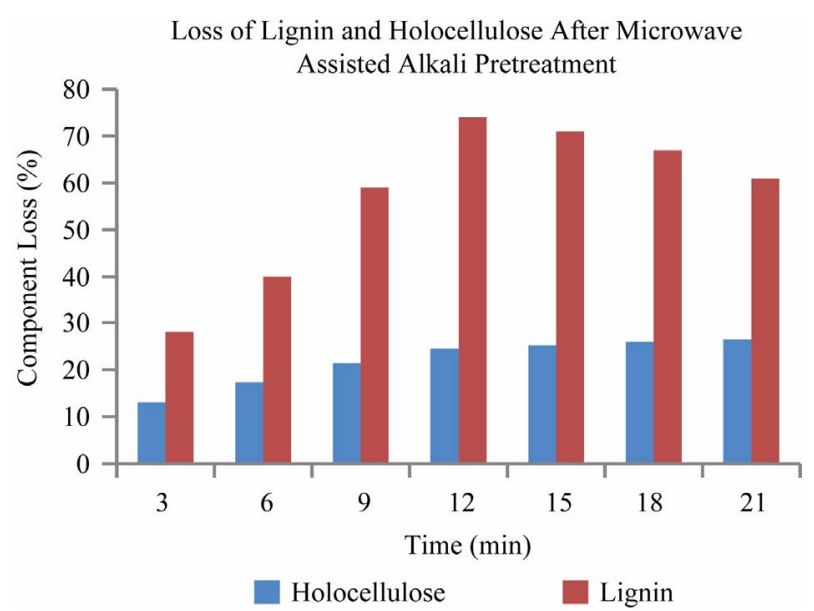

Figure 1. Lignin and holocellulose reduction caused by microwave-alkaline $(3 \% \mathrm{NaOH})$ pretreatment of EFB.

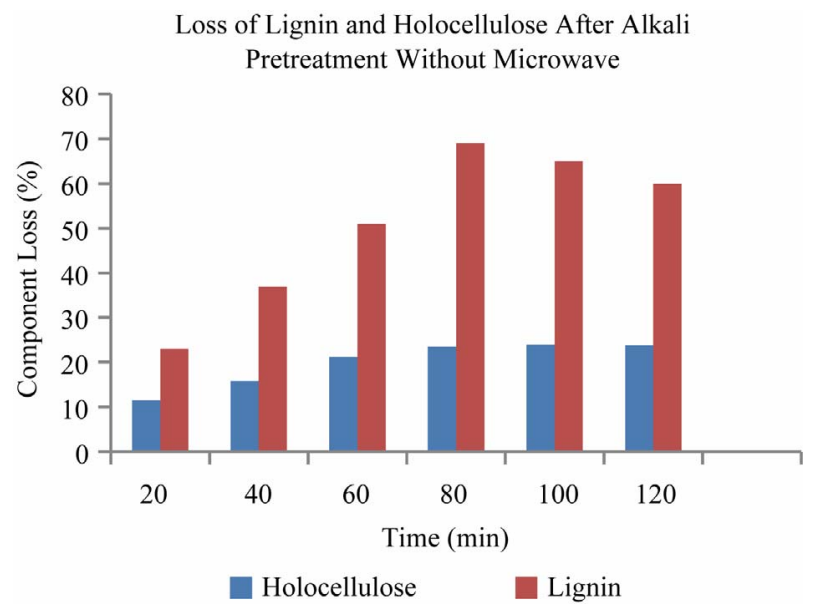

Figure 2. Lignin and holocellulose reduction caused by conventional heating at $50^{\circ} \mathrm{C}$ with $3 \% \mathrm{NaOH}$ pretreatment of EFB.

curred at 3 - 4 min of the treatment [29]. In a study using Coastal Bermuda grass, pretreatment with higher $\mathrm{NaOH}$ concentrations (above 3\%) and longer microwave exposure times, resulted in lower solid recovery, thus leading to less reducing sugars yield [46]. The severity of the pretreatment process is influenced by both the alkali concentration and pretreatment time. Extended pretreatment likely resulted in loss of carbohydrates to the pretreatment liquor, thereby will reduce the sugar yields during hydrolysis.

The major effect of pretreatment using alkali is the removal of lignin from the biomass. In the process, the structural disruption improves accessibility of carbohydrates to enzymes. The use of microwave radiation is a promising pretreatment process that utilizes thermal and non-thermal effects generated by microwaves in aqueous environments. Superiority of activating polysaccharides by microwave irradiation may be due to direct delivery of microwave energy to polysaccharides through molecular interactions with electromagnetic field. The electric and magnetic field components of microwaves apply forces that are rapidly changing direction at the rate of $2.4 \times 10^{9}$ times per second [47]. The vibration of polar molecules and the movement of ions results in the generation of heat and extensive collisions. These effects can accelerate chemical, biological and physical processes [48]. From this study it was shown that the most efficient method for utilizing microwave radiation as a pretreatment process for oil palm EFB was at lower power levels $(180 \mathrm{~W})$ in combination with dilute $\mathrm{NaOH}(3 \%)$.

The choice of using $\mathrm{NaOH}$ as the medium is based on the fact that the effects of microwave-based processes depend on the polar characteristics of the system. These polar characteristics are defined by the dipole moments of species in the system. $\mathrm{NaOH}$ has a dipole moment of 6.89 Debye, which is much higher than the dipole moments for $\mathrm{H}_{2} \mathrm{SO}_{4}$ and deionized water, which are 3.09 and 2.12, respectively [49]. [24] noticed under SEM analysis, that the surface of the lignocellulosic material had become roughened and loosened after treatment with alkali. They also observed that alkali treatment followed by microwave irradiation caused the lignocellulosic material to become thinner and striated. It is believed that the lignin was degraded and hence increased the exposure of cellulose and hemicelluloses in the lignocellulosic materials [24].

Hence the advantage of using microwave is that it reduces the time required for the delignification process significantly and uses less electrical energy. Similarly, pretreatment of Bermuda grass using microwave at a power level of $250 \mathrm{~W}$ with $1 \% \mathrm{NaOH}$ for $10 \mathrm{~min}$ removed nearly $65 \%$ of the lignin and retained $87 \%$ of the glucan [45]. [14] also reported that microwave assisted alkali pretreatment of wheat straw removed more lignin and hemicellulose from biomass with shorter pretreatment time than the alkali one by conventional heating.

\section{FTIR Spectroscopy Characterization of Microwave Pretreated EFB}

FTIR spectroscopy was used to investigate the changes of cellulosic structures during microwave pretreatment. Figure 3 shows the FTIR spectra of native EFB and microwave assited alkali pretreated EFB. A strong broad absorption at $3340-3412 \mathrm{~cm}^{-1}$ is observed which is related to the stretching of $\mathrm{H}$-bonded $\mathrm{OH}$ groups, and another prominent one around $2900 \mathrm{~cm}^{-1}$ due to the $\mathrm{C}-\mathrm{H}$ stretching in methyl and methylene groups [50,51]. In addition, there are many well-defined peaks in the fingerprint region between 1800 and $600 \mathrm{~cm}^{-1}$. The distinctive bands in the fingerprint region and the components to which these peaks are attributable are shown in Table 2 [50-53]. The profile of the FTIR spectra was different 
Table 2. FTIR wavenumber characterization [50-53].

\begin{tabular}{|c|c|}
\hline $\begin{array}{l}\text { Wavenumber } \\
\quad\left(\mathrm{cm}^{-1}\right)\end{array}$ & Compound \\
\hline 3336 & O-H streching \\
\hline $2880-2940$ & $\mathrm{C}-\mathrm{H}$ stretching in methyl and methylene groups \\
\hline 1734 & $\begin{array}{l}\mathrm{C}=\mathrm{O} \text { stretching in unconjugated ketones, carbonyls } \\
\text { and in ester groups, frequently of carbohydrate origin. }\end{array}$ \\
\hline 1598 & Aromatic skeletal vibration plus $\mathrm{C}=\mathrm{O}$ stretch \\
\hline 1502 & Aromatic skeletal vibration plus $\mathrm{C}=\mathrm{O}$ stretch \\
\hline 1372 & $\mathrm{CH}$ deformation in cellulose and hemicellulose \\
\hline 1316 & $\mathrm{C}-\mathrm{H}$ vibration in cellulose \\
\hline 1270 & $\begin{array}{l}\mathrm{C}-\mathrm{O} \text { stretch in lignin; } \mathrm{C}-\mathrm{O} \text { linkages in guaiacyl } \\
\text { aromatic methoxy groups. }\end{array}$ \\
\hline 1235 & $\mathrm{C}=$ stretch in lignin and xylan \\
\hline 1157 & $\mathrm{C}-\mathrm{O}-\mathrm{C}$ vibration in cellulose and hemicellulose \\
\hline 1034 & $\begin{array}{l}\text { Aromatic } \mathrm{C}-\mathrm{H} \text { in plane deformation, } \mathrm{C}-\mathrm{O} \text { deformation; } \\
\text { primary alcohol }\end{array}$ \\
\hline 897 & $\beta$-glycosidic linkages \\
\hline
\end{tabular}

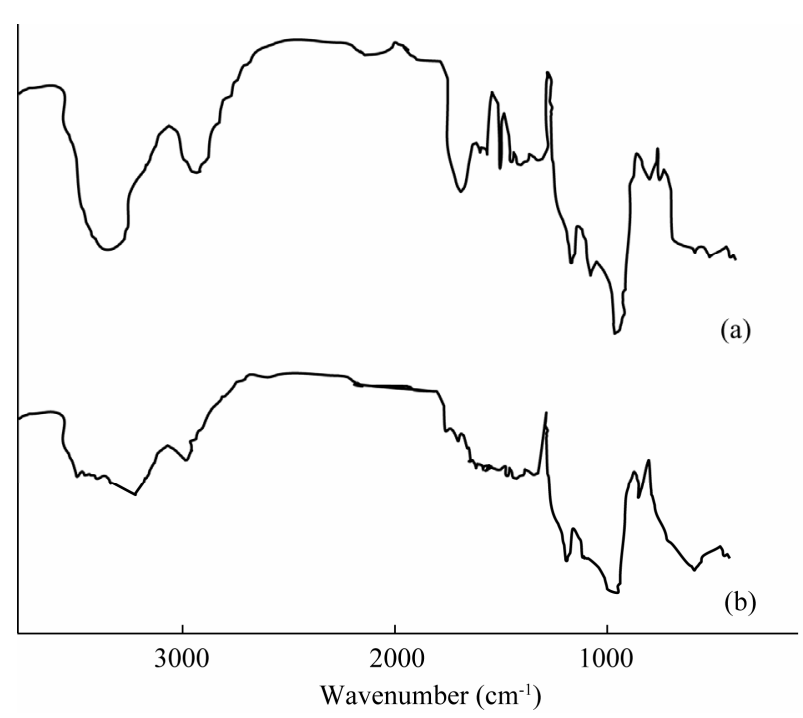

Figure 3. FTIR spectra of (a) native and (b) microwave assisted alkali pretreated EFB.

for native and microwave assisted alkali pretreated EFB. This indicates that there were structural changes of cellulose after pretreatment. Major changes were broadening of band at $3200-3400 \mathrm{~cm}^{-1}$ which was associated with the $\mathrm{O}-\mathrm{H}$ stretching of the hydrogen bonds. The peak of $-\mathrm{CH}_{2}$ stretching near $2900 \mathrm{~cm}^{-1}$ were easily distinguishable from native as well as microwave assisted alkali pretreated EFB. Bands at $1000-1200 \mathrm{~cm}^{-1}$ were related to structural features of cellulose and hemicelluloses. The enhancement of absorption peaks at 1000 $1100 \mathrm{~cm}^{-1}$ after pretreatment indicate the increase in cel- lulose content in the solid residue [54].

The peak of $\mathrm{O}-\mathrm{H}$ stretching at $3300 \mathrm{~cm}^{-1}$ and the peak of $-\mathrm{CH}_{2}$ stretching near $2900 \mathrm{~cm}^{-1}$ are the distinguished features of cellulose. The $\mathrm{O}-\mathrm{H}$ bond at $3400 \mathrm{~cm}^{-1}$ is affected by microwave assisted alkali treatment and its intensity is decreased. It has been reported that microwave irradiation enhances the saponification of intermolecular ester bonds cross-linking xylan hemicelluloses and other components such as lignin and other hemicelluloses and hence the $\mathrm{O}-\mathrm{H}$ band intensity tends to decrease due to its consumption in this reaction.

\subsection{Enzymatic Hydrolysis}

After identifying the optimum pretreatment conditions, optimization of the enzymatic saccharification was carried out on the pretreated EFB biomass. Hydrolysis of cellulosic biomass prior to fermentation to ethanol is a very important step because the yeast, $S$. cerevisiae, is non-amylolytic microbe. Figure 4, presents the influence of the microwave treatment $(100 \mathrm{~W})$ on the yield of reducing sugar from the pretreated EFB biomass. Low level of MW power was used (100 Watt) in order to avoid the enzyme denaturation and to minimize the thermal effects of the process. At this level, the temperature of the mixture was found to be in the range of $41^{\circ} \mathrm{C}$ $45^{\circ} \mathrm{C}$; which is crucial to avoid enzyme denaturation. As shown in Figure 4, at the end of the total $4 \mathrm{hr}$ incubation under microwave exposure $(100 \mathrm{~W}$ output power; temperature $41^{\circ} \mathrm{C}-45^{\circ} \mathrm{C}$ ) the highest yield of reducing sugar was found to be about $411 \mathrm{mg}$ per gram of treated EFB biomass. The amount of cellulose enzyme dosage for the optimal yield was 20 FPU. As for the non-microwave enzymatic hydrolysis, after the incubation period of $48 \mathrm{hr}$, the yield of reducing sugar was found to be $178 \mathrm{mg}$ per gram of microwave pretreated EFB biomass. This yield was obtained by using cellulose enzyme at the dosage of 35 FPU. This shows that microwave assisted enzymatic hydrolysis enhances the yield of reducing sugar by about

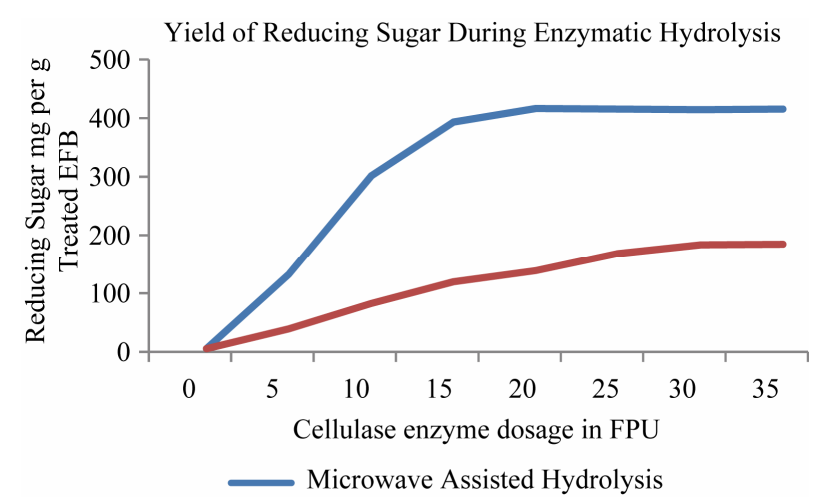

Figure 4. Reducing sugar yield at various cellulose enzyme dosages for microwave assisted hydrolysis and non microwave hydrolysis. 
2.2 fold as compared with the non-microwave enzymatic hydrolysis process.

Using microwave irradiation, it is often possible to accelerate the rate of reactions and hence reduce the reaction time and the energy consumption $[55,56]$. Nonthermal effects or microwave effect has been observed in a number of microwave assisted catalytic or enzymatic reactions [33,57]. It has been proposed that at low power level of microwave irradiation, the significant contributor is the non-thermal effects, while the thermal effect plays only a minor role. Non-thermal effects refer to interactions resulting in non-equilibrium energy fluctuation distributions or deterministic, time-averaged drift motion of matter (or both) $[58,59]$. This provides the molecule collision under microwave irradiation extra driving force, which results in higher rate of reaction under microwave irradiation as long as the enzyme is not deactivated by microwave. Under low power level of microwave irradiation, the active site of the enzyme molecules may undergo conformational changes and the microwave energy can modulate the configuration of enzyme molecules by accelerating the molecular rotation, which can provide more chance to make the substrates fit to the enzyme per unit of time $[33,57,60]$. Another aspect to note is that the amount of enzyme required to achieve maximum yield was also less for the case of microwave assisted hydrolysis. This suggests that the microwave irradiation was able to lower down the activation energy of the reaction and hence increases the rate of reaction. In their work on biodiesel production, [61], have confirmed that preheating samples with microwave irradiation give the molecules a more flattened configuration, which improves reactivity due to the resultant lower dipole moment and lower activation energy.

As shown in Table 3, the overall enhancement by the microwave treatment during the microwave assisted alkali pretreatment and microwave assisted enzymatic hydrolysis is 5.8 fold.

The microwave experiments were carried out at low power level and constant temperature. The removal of

Table 3. Amount of reducing sugar yield under different treatments.

\begin{tabular}{cc}
\hline Treatments & $\begin{array}{c}\text { Reducing Sugar } \\
\text { (mg per gram EFB) }\end{array}$ \\
\hline $\begin{array}{c}\text { Non Microwave Alkali Pretreatment } \\
\text { and Enzymatic Hydrolysis }\end{array}$ & 71 \\
$\begin{array}{c}\text { Non Microwave Alkali Pretreatment and } \\
\text { Microwave Assisted Enzymatic Hydrolysis }\end{array}$ & 104 \\
$\begin{array}{c}\text { Microwave Assisted Alkali Pretreatment and } \\
\text { Enzymatic Hydrolysis }\end{array}$ & 178 \\
$\begin{array}{c}\text { Microwave Assisted Alkali Pretreatment and } \\
\text { Microwave Assisted Enzymatic Hydrolysis }\end{array}$ & 411 \\
\hline
\end{tabular}

lignin accompanied by the disruption of the biomass structure improves the accessibility to hydrolytic enzymes. These factors along with changes in the crystallinity of cellulose during microwave-alkaline pretreatment contribute to increased sugar yields. Other reports have also shown that relatively short duration of the microwave treatment was superior in destroying the starch crystalline arrangement in the hydrolysis of starch to reducing sugar [28].

\section{Conclusions}

This study examined the potential of microwave-based pretreatment and microwave assisted enzymatic reaction on EFB of Oil Palm. It was determined that the most efficient method for utilizing microwave radiation as a pretreatment process was at lower power levels in combination with dilute $\mathrm{NaOH}$. The highest reducing sugar yields were obtained for microwave- $\mathrm{NaOH}$ pretreatment at $180 \mathrm{~W}$ for 12 minutes with the biomass immersed in $3 \% \mathrm{NaOH}$ solution.

Results comparable to conventional $\mathrm{NaOH}$ pretreatments were obtained at only one-seventh of the residence time. The present study had also highlighted the importance of well controlled microwave assisted enzymatic reaction to enhance the overall reaction rate of the process. It should be noted that enzymatic hydrolysis of lignocelulosic material using typical enzymes was successfully carried out under microwave condition. The effect of microwave irradiation strongly depends on; microwave power level-higher levels of MW may cause denaturation of the enzyme. The dominant factor in the microwave assisted reaction in this study may be treated as non-thermal effects. The Microwave Irradiation-Enzyme Coupling Catalysis (MIECC) or microwave assisted enzymatic reaction effects on reducing sugar production had shown a reaction rate increase of 2.3 fold and with less enzyme requirement.

\section{REFERENCES}

[1] B. Hahn-Hagerdal, M. Galbe, M. F. Gorwa-Grauslund, G. Liden and G. Zacchi, "Bio-Ethanol-the Fuel of Tomorrow from the Residues of Today," Trends in Biotechnology, Vol. 24, No. 12, 2006, pp. 549-556. doi:10.1016/j.tibtech.2006.10.004

[2] M. Balat, H. Balat and C. Oz, "Progress in Bio Ethanol Processing," Progress in Energy and Combustion Science, Vol. 34, No. 5, 2008, pp. 551-573. doi:10.1016/j.pecs.2007.11.001

[3] Y. Sun and J. Cheng, "Hydrolysis of Lignocellulosic Materials for Ethanol Production: A Review," Bioresource Technology, Vol. 83, No. 1, 2002, pp. 1-11. doi:10.1016/S0960-8524(01)00212-7

[4] N. Mosier, C. Wyman, B. Dale, R. Elander, Y.Y. Lee, M. 
Holtzapple and M. Ladisch, "Features of Promising Technologies for Pretreatment of Lignocellulosic Biomass," Bioresource Technology, Vol. 96, No. 6, 2005, pp. 673686. doi:10.1016/j.biortech.2004.06.025

[5] S. Kim and B. E. Dale, "Environmental Aspects of Ethanol Derived from No-tilled Corn Grain: Non Renewable Energy Consumption and Greenhouse Gas Emissions," Biomass and Bioenergy, Vol. 28, No. 5, 2005, pp. 475489. doi:10.1016/j.biombioe.2004.11.005

[6] K. A. Gray, L. Zhao and M. Emptage, "Bioethanol," Current Opinion in Chemical Biology, Vol. 10, No. 4, 2006, pp. 141-146. doi:10.1016/j.cbpa.2006.02.035

[7] T. L. Chew and S. Bhatia, "Catalytic Processes towards the Production of Biofuels in a Palm Oil and Oil Palm Biomass-Based Biorefinery," Bioresource Technology, Vol. 99, No. 17, 2008, pp. 7911-7922. doi:10.1016/j.biortech.2008.03.009

[8] A. Yahya, P. S. Chong, T. A. Ishola and H. Suryanto, "Effect of Adding Palm Oil Mill Decanter Cake Slurry with Regular Turning Operation on the Composting Process and Quality of Compost from Oil Palm Empty Fruit Bunches," Bioresource Technology, Vol. 101, No. 22, 2010, pp. 8736-8741. doi:10.1016/j.biortech.2010.05.073

[9] M. Z. Alam, A. M. Suleyman, F. M. Mariatul and R. Wahid, "Activated Carbons Derived from Oil Palm EmptyFruit Bunches," Journal of Environmental Sciences, Vol. 19, No. 1, 2007, pp. 103-108. doi:10.1016/S1001-0742(07)60017-5

[10] M. N. Bari, M. Z. Alam, A. M. Suleyman, P. Jamal and A. A. Mamun, "Improvement of Production of Citric Acid from Oil Palm Empty Fruit Bunches: Optimization of Media by Statistical Experimental Designs," Bioresource Technology, Vol. 100, No. 12, 2009, pp. 3113-3120. doi:10.1016/j.biortech.2009.01.005

[11] O. Tomoko, M. Nakanishi, Y. Fukuda and K. Matsumoto, "Gasification of Oil Palm Residues (Empty Fruit Bunch) in an Entrained-Flow Gasifier," Fuel, Vol. 104, 2013, pp. 28-35. doi:10.1016/j.fuel.2010.08.028

[12] Y. Syafwina, T. Honda, M. Watanabe and M. Kuwahara, "Pretreatment of Oil Palm Empty Fruit Bunch by WhiteRot Fungi for Enzymatic Saccharification," Wood Research, Vol. 89, 2002, pp. 19-20.

[13] B. Yang and C. E. Wyman, "Pre-Treatment: The Key to Unlocking Low-Cost Cellulosic Ethanol, Biofuels," Bioprod, Bioref, Vol. 2, No. 1, 2008, pp. 26-40. doi:10.1002/bbb.49

[14] S. Zhu, Y. Wu, Z. Yu, Q. Chen, G. Wu, F. Yu, C. Wang and S. Jin, "Microwave Assisted Alkali Pre-treatment of Wheat Straw and Its Enzymatic Hydrolysis," Process Biochemistry, Vol. 94, No. 3, 2006, pp. 437-442.

[15] Y. Zhao, Y. Wang, J. Y. Zhu, A. Ragauskas and Y. Deng, "Enhanced Enzymatic Hydrolysis of Spruce by Alkaline Pretreatment at Low Temperature," Biotechnology and Bioengineering, Vol. 99, No. 6, 2008, pp. 1320-1328. doi:10.1002/bit.21712

[16] P. Alvira, E. Tomas-Pejo, M. Ballesteros and M. J. Negro, "Pretreatment Technologies for an Efficient Bioethanol Production Process Based on Enzymatic Hydrolysis: A Review," Bioresource Technology, Vol. 101, No. 13, 2010, pp. 4851-4861. doi:10.1016/j.biortech.2009.11.093

[17] P. Kumar, D. M. Barrett, M. J. Delwiche and P. Stroeve, "Methods for Pretreatment of Lignocellulosic Biomass for Efficient Hydrolysis and Biofuel Production," Industrial \& Engineering Chemistry Research, Vol. 48, No. 8, 2009, pp. 3713-3729. doi:10.1021/ie801542g

[18] C. E. Wyman, "Handbook on Bio Ethanol: Production and Utilization in Applied Energy Technology," Series Taylor and Francis, Washington DC, 1996.

[19] A. T. W. M. Hendriks and G. Zeeman, "Pretreatments to Enhance the Digestibility of Lignocellulosic Biomass," Bioresource Technology, Vol. 100, No. 1, 2009, pp. 1018. doi:10.1016/j.biortech.2008.05.027

[20] X. Zhao, K. Cheng and D. Liu, "Organosolv Pretreatment of Lignocellulosic Biomass for Enzymatic Hydrolysis," Applied Microbiology and Biotechnology, Vol. 82, No. 5, 2009, pp. 815-827. doi:10.1007/s00253-009-1883-1

[21] G. A. Aita and M. Kim, "Pretreatment Technologies for the Conversion of Lignocellulosic Materials to Bio ethanol Sustainability of the Sugar and Sugar-Ethanol Industries," American Chemical Society Publications, New Orleans, 2010, pp. 117-145.

[22] M. J. Taherzadeh and K. Karimi, “Acid-Based Hydrolysis Process for Ethanol from Lignocellulosic Materials: A Review," Bioresources, Vol. 2, No. 3, 2007, pp. 472-499.

[23] A. K. Datta, "Fundamentals of Heat and Moisture Transport for Microwaveable Food Product and Process Development," In: A. K. Datta and R. C. Anantheswaran, Eds., Handbook of Microwave Technology for Food Applications, Marcel Dekker Inc., New York, 2001.

[24] Z. H. Hu and Z. Y. Wen, "Enhancing Enzymatic Digestibility of Switchgrass by Microwave-Assisted Alkali Pretreatment," Biochemical Engineering Journal, Vol. 38, No. 3, 2008, pp. 369-378. doi:10.1016/j.bej.2007.08.001

[25] H. Ooshima, K. Aso, Y. Harano and T. Yamamoto, "Microwave Treatment of Cellulosic Materials for Their Enzymatic Hydrolysis," Biotechnology Letters, Vol. 6, No. 5, 1984, pp. 289-294. doi:10.1007/BF00129056

[26] J. Xiong, J. Ye, W. Z. Liang and P. M. Fan, "Influence of Microwave on the Ultrastructure of Cellulose I," Journal of South China University of Technology, Vol. 28, No. 3, 2000, pp. 84-89.

[27] J. Azuma, F. Tanaka and T. Koshijima, "Enhancement of Enzymatic Susceptibility of Lignocellulosic Wastes by Microwave Irradiation," Journal of Fermentation Technology, Vol. 62, No. 4, 1984, pp. 377-384.

[28] T. Palav and K. Seetharaman, "Impact of Microwave Heating on the Physico-Chemical Properties of a StarchWater Model System," Carbohydrate Polymers, Vol. 67, No. 4, 2007, pp. 596-604. doi:10.1016/i.carbpol.2006.07.006

[29] P. Binod, K. Satyanagalakshimi, R. Sindhu, K. Usha Janu, R. K. Sukumaran and A. Pandey, "Short Duration Microwave Assisted Pretreatment Enhances the Enzymatic Saccharification and Fermentable Sugar Yield from Sugarcane Bagasse," Renewable Energy, Vol. 37, No. 12, 2012, pp. 109-116. doi:10.1016/j.renene.2011.06.007

[30] N. E. Leadbeater, L. M. Stencel and E. C. Wood, "Prob- 
ing the Effects of Microwave Irradiation on EnzymeCatalysed Organic Transformations: The Case of LipaseCatalysed Transesterification Reactions," Organic and Biomolecular Chemistry, Vol. 5, No. 7, 2007, pp. 10521055. doi:10.1039/b617544a

[31] G. D. Yadav and A. D. Sajgure, "Synergism of Microwave Irradiation and Enzyme Catalysis in Synthesis of Isoniazid," Journal of Chemical Technology \& Biotechnology, Vol. 82, No. 11, 2007, pp. 964-970. doi: $10.1002 /$ jetb. 1738

[32] I. Roy and M. Gupta, "Applications of Microwaves in Biological Sciences," Current Science, Vol. 85, No. 12, 2003, pp. 1685-1693.

[33] G. D. Yadav and P. Lathi, "Microwave Assisted Enzyme Catalysis for Synthesis of n-Butyl Dipheyl Methyl Mercapto Acetate in Non-Aqueous Media," Clean Technologies and Environmental Policy, Vol. 9, No. 4, 2007, pp. 281-287. doi:10.1007/s10098-006-0082-3

[34] N. Saifuddin, A. Z. Raziah and H. N. Farah, "Production of Biodiesel from High Acid Value Waste Cooking Oil Using an Optimized Lipase Enzyme/Acid Catalyzed Hybrid Process," E-Journal of Chemistry, Vol. 6, No. S1, 2009, pp. S485-S495. doi:10.1155/2009/801756

[35] A. Sluiter, B. Hames, R. Ruiz, C. Scarlata, J. Sluiter, D. Templeton and D. Crocker, "Determination of Structural Carbohydrates and Lignin in Biomass," National Renewable Energy Laboratory, Golden, 2008. http://www.nrel.gov/biomass/pdfs/42618.pdf

[36] ASTM (American Society for Testing and Materials), "Method of Test for Holocellulose in Wood," 1978. http://www.astm.org/Standards/D1 104.htm.

[37] D. D. Y. Ryu and M. Mandels, "Cellulases-Biosynthesis and Applications," Enzyme and Microbial Technology, Vol. 2, No. 2, 1980, pp. 91-102. doi:10.1016/0141-0229(80)90063-0

[38] G. M. Miller, "Use of Dinitrosalicylic Acid Reagent for Determination of Reducing Sugar," Analytical Chemistry, Vol. 31, No. 3, 1959, pp. 426-428. doi: $10.1021 / \mathrm{ac} 60147 \mathrm{a} 030$

[39] R. A. Silverstein, Y. Chen, R. R. Sharma-Shivappa, M. D. Boyette and J. Osborne, "A Comparison of Chemical Pretreatment Methods for Improving Saccharification of Cotton Stalks," Bioresource Technology, Vol. 98, No. 16, 2007, pp. 3000-3011. doi:10.1016/j.biortech.2006.10.022

[40] D. A. Salvi, G. M. Aita, D. Robert and V. Bazan, "Ethanol Production from Sorghum by a Dilute Ammonia Pretreatment," Journal of Industrial Microbiology \& Biotechnology, Vol. 37, No. 1, 2009, pp. 27-34. doi:10.1007/s10295-009-0645-5

[41] C. Chen, D. Boldor, G. Aita and M. Walker, "Ethanol Production from Sorghum by a Microwave-Assisted Dilute Ammonia Pretreatment," Bioresource Technology, Vol. 110, 2012, pp. 190-197. doi:10.1016/j.biortech.2012.01.021

[42] Z. Hu, Y. Wang and Z. Wen, "Alkali $(\mathrm{NaOH})$ Pretreatment of Switchgrass by Radio Frequency-Based Dielectric Heating," Applied Biochemistry and Biotechnology, Vol. 148, No. 1-3, 2008, pp. 71-81. doi:10.1007/s12010-007-8083-1
[43] C. Li, B. Knierim, C. Manisseri, R. Arora, H. V. Scheller, M. Auer, K. P. Vogel, B. A. Simmons and S. Singh, "Comparison of Dilute Acid and Ionic Liquid Pretreatment of Switchgrass: Biomass Recalcitrance, Delignification and Enzymatic Saccharification," Bioresource Technology, Vol. 101, No. 13, 2010, pp. 4900-4906. doi:10.1016/j.biortech.2009.10.066

[44] J. Xu, J. J. Cheng, R. R. Sharma-Shivappa and J. C. Burns, "Sodium Hydroxide Pretreatment of Switch Grass for Ethanol Production," Energy Fuels, Vol. 24, No. 3, 2010, pp. 2113-2119. doi:10.1021/ef9014718

[45] D. R. Keshwani and J. J. Cheng, "Microwave-Based Alkali Pretreatment of Switchgrass and Coastal Bermuda Grass for Bio Ethanol Production," Biotechnology Progress, Vol. 26, No. 3, 2009, pp. 644-652. doi:10.1002/btpr.371

[46] Z. Wang, D. R. Keshwani, A. P. Redding and J. J. Cheng, "Sodium Hydroxide Pretreatment and Enzymatic Hydrolysis of Castal Bermuda Grass," Bioresource Technology, Vol. 101, No. 10, 2010, pp. 3583-3585. doi:10.1016/j.biortech.2009.12.097

[47] S. A. Galema, "Microwave Chemistry," Chemical Society Reviews, Vol. 26, No. 3, 1997, pp. 233-238. doi:10.1039/cs9972600233

[48] V. Sridar, "Microwave Radiation as a Catalyst for Chemical Reactions," Current Science, Vol. 74, No. 5, 1998, pp. 446-450.

[49] National Institute of Standards and Technology, "Standard Reference Database 101," 2006. http://srdata.nist.gov/cccbdb

[50] L. Wang, G. Han and Y. Zhang, "Comparative Study of Composition, Structure and Properties of Apocynum Venetum Fibers under Different Pretreatments," Carbohydrate Polymers, Vol. 69, No. 2, 2007, pp. 391-397. doi:10.1016/j.carbpol.2006.12.028

[51] K. K. Pandey, "Study of the Effect of Photo-Irradiation on the Surface Chemistry of Wood," Polymer Degradation and Stability, Vol. 90, No. 1, 2005, pp. 9-20. doi:10.1016/i.polymdegradstab.2005.02.009

[52] D. Fengel and G. Wegener, "Wood-Chemistry, Ultrastructure Reactions," Kessel Verlag, Remagen, 2003.

[53] K. K. Pandey and A. J. Pitman, "Examination of Lignin Content in a Softwood and a Hard Wood Decayed by a Brown-Rot Fungus with Acetyl Bromide Method and Fourier Transform Infrared Spectroscopy," Journal of Polymer Science Part A: Polymer Chemistry, Vol. 42, No. 10, 2004, pp. 2340-2346. doi:10.1002/pola.20071

[54] Y. Sun, L. Lin, H. B. Deng, J. Z. Li, B. H. He and R. C. Sun, "Structural Changes of Bamboo Cellulose in Formic Acid," Bioresources, Vol. 3, No. 2, 2008, pp. 297-315.

[55] N. Saifuddin and K. H. Chua, "Production of Ethyl Ester (Biodiesel) from used Frying Oil: Optimization of Transesterification Process using Microwave Irradiation," Malaysian Journal of Chemistry, Vol. 6, No. 1, 2004, pp. 7782.

[56] J. Hernando, P. Leton, M. P. Matia, J. L. Novella and J. Alvarez-Builla, "Biodiesel and FAME Synthesis Assisted by Microwaves: Homogeneous Batch and Flow Processes," Fuel, Vol. 86, No. 10-11, 2007, pp. 1641-1644. 
doi:10.1016/j.fuel.2006.11.003

[57] N. Saifuddin, L. W. Zhan and K. K. X. Ning, "Heat-Modeling of Microwave Assisted Epoxidation of Palm Acid Oil," American Journal of Applied Sciences, Vol. 8, No. 3, 2011, pp. 217-229. doi:10.3844/ajassp.2011.217.229

[58] N. Kuhnert, "Microwave-Assisted Reactions in Organic Synthesis-Are There Any Non thermal Microwave Effects? Angew," Angewandte Chemie International Edition, Vol. 41, No. 11, 2002, pp. 1863-1866.

doi:10.1002/1521-3773(20020603)41:11<1863::AID-AN IE1863>3.0.CO;2-L

[59] J. H. Booske, R. F. Cooper and S. A. Freeman, "Micro- wave Enhanced Reaction Kinetics in Ceramics," Materials Research Innovations, Vol. 1, No. 2, 1997, pp. 77-84. doi:10.1007/s100190050024

[60] A. De la Hoz, A. Diaz-Ortiz and A. Moreno, "Selectivity in Organic Synthesis under Microwave Irradiation," Current Organic Chemistry, Vol. 8, No. 10, 2004, pp. 903-918. doi:10.2174/1385272043370429

[61] Y. Asakuma, Y. Ogawa, K. Maeda, K. Fukui and H. Kuramochi, "Effects of Microwave Irradiation on Triglyceride Transesterification: Experimental and Theoretical Studies," Biochemical Engineering Journal, Vol. 58-59, No. 15, 2011, pp. 20-24. doi:10.1016/j.bej.2011.08.003 